\title{
FOREIGN DEPARTMENT
}

\author{
IN CHARar or \\ LAVINIA L. DOCK

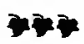 \\ MODERN MOVEMENTS IN THE OLD WORLD

\section{THE NURSING ASSOCIATION OF THE HAMBURG STATE HOSPITALS}

\author{
IBY HEDWIG VON SCHLICHTING
}

Superintendent of the Nursing Department.

[Wr feel privileged in having the permission of the author of the following article to translate it for the readers of the Joursal. It was written for Das Rothe Kreuz of last February. Few American nurses realize how much harder is the work and how much longer are the hours of the average German nurse than ours; and only tlose who have come into contact with that tremendous weight of fixed custom will rightly estimate the courage and force of character shown by Friulein von Schlichting in making this strong appeal for less hard conditions of work. We bclieve this is the first time that a German nurse has thus publicly urged a reform in hospital overwork, and the wholc personality of the "Frau Oberin" of the Hamburg Statc hospitals, her peculiar and extensive power, rcsponsibility, and influence over others, make her a strong champion of the overburdened but uncomplaining German "sister."

Fräulein von Schlichting is the daughter of a German officer of high rank. Her heart was set upon nursing from an early age, and she studied in the Augusta Hospital of Bcrlin, a nursing school open only to pupils of noble birth. She held several positions of responsibility before taking charge of the Hamburg hospitals, where she organized a modern training-school of special distinction.-ED.]

THE development of social conditions has been such that the urgent necessity. of self-maintenance presses to-day upon thousands of women, and it is therefore of the deepest importance that lay orders of nursing sisters should be multiplied, where women who do not feel called to renounce the world may find a career and a secure future, without having to submit to the restrictions of strictly religious orders.

Of such, one of the largest, and I think I may say one of the best organized, owing to exceptionally favorable financial conditions, is the Hamburg Nursing Association, which has now been in existence for five and a half years.

The fundamental purpose in establishing this nursing school was to improve the service of the public hospitals by creating a staff of refined and specially educated women for the care of the patients. Until 1895 there were only untrained attendants in the Hamburg hospitals. The New General Hospital at Eppendorf contains nineteen hundred beds, and in June, 1894, I was called to Hamburg to reconstruct the nursing according to the new system. After a year of teaching 
and preparation the Nursing Association began its definite existence with thirtyfive sisters and twenty pupils. An extensive exodus of the old attendants now took place, and in order to fll vacancies the opportunity for applicants to enter the school was made known all over Germany. Thanks largely to the liberal provisions of our organization plan, devised to meet the need i f many women, it met with widespread favor, and applications were so numerous that a choice of the very best material was made possible. The association fiourished most satisfactorily, and now numbers two hundred and fifty sisters.

The entrance-age is between twenty and thirty-five years. After one and a half years of probation and instruction, the appointment foslows (as sister) for anotlier one and a half years. [The full term is thus three years, and at the end of this time the nurse can sever her connection with the school. She then ceases to be a member of the "Verein" and loses its benefits. The greater number, however, remain in the "Verein."-ED.] In the first half year as " sisters" they receive no salary, but in the second half year sixty marks (a mark is about twenty-five cents), and in the third one hundred and twenty marks. After that, for those who remain, the salary gradually rises with length of service to three hundred and fifty marks a year.

After ten years' service, in case of disability the sisters receive a pension of from eight hundred to one thousand marks, or if invalided before ten years, a varying compensation is made by the Board of Trustees.

The sisters have their home without cxpense, and are cared for in illness. The hospital uniform of wash material is supplied upon entrance, and at the end of the first one and a half years the street uniform is also given.

Day and night duty are distinct; the first lasts from six A.M. to nine P.M., with an hour off after dinner. Once a weck a half day is given from two P.M. to midnight. The night nurses are on duty from ninc P.M. to nine A.x. Their time off is given on Sunday and Monday, the night nurses being relieved by the day nurses at midnight on Sunday, so that each has just half the night.

The sisters have a yearly vacation of four weeks. The care of the association has been extended to one after another of the State institutions, until now it has charge of the nursing in the Lying-In Hospital, the Asylum for the Insane, a sanatorium for phthisis, and the old General Hospital. Our sisters have also been called outside of Germany, in Trebchen, in the German Hospital in Buenos Ayres, and in the Turkish University Hospital in Constantinople. They are under the direction of a German physician, who teaches medicine in the university. The nurses also are there as teachers. Their work is to train Turkish soldiers as military hospital orderlies.

For four years past the Colonial Nursing Association has sent its sisters to Eppendorf to be trained.

In November, 1899, six of our sisters went to the field in the Transvaal at the request of the Central Committee of the Red Cross.

These varied fields of work are a delight to me, and bring refreshment by their variety.

Provision is also made for the recreation and rest of the nurses. Their monthly vacations may be taken without cost at a seaside place where the association possesses a cottage. In their hours off duty the nurses' home-Erica House-offers comfortable rooms, with piano and library, where those beyond reach of their own families may yet spend homelike hours. In off-duty time the nurses are allowed every freedom which a well-bred woman may desire. Concerts and visits to the theatre are encouraged, and I am glad to see them interested 
in things which have no connection with hospital work. In 1895 a singing-society was formed among the sisters, practising weekly; and from time to time popular lectures on educational or scientific subjects are given. Extra time is given on Sunday to those who wish to attend church, but this is not compulsory. In my opinion the truest religion is shown in practical, helpful service and faithful discharge of duty.

That our hospital patients are better nursed since the oncoming of our sisters is a foregone conclusion. The anticipations of its founders are fully realized,a proof that care and consideration for the nurses are closely related to the interests of the hospital.

From the beginning I have held it to be my duty, in and through our association, to work as woman for women. That in this constant endeavor I have had the powerful support of many influential men of Hamburg, especially Senator Dr. Lappenberg and the directors of the Hamburg institutions, I must now gratefully acknowledge. Only through the warm interest shown on many sides in our nurses could the various provisions for thcir comfort have been obtained. Much has been done, but much yet remains to be done.

Let us follow the life of a nurse for a brief period of observation. Fourteen to fifteen hours daily make up her working time, and after this work is done, in the scanty time "off duty," with its excessive physical exertion and its continual drain upon the sympathies and the nervous energy, the craving for rest overbalances evcry other desire. After becoming a "sister" the human creature has no more rights. There are, it is true, nurses who find entire happiness in their work, but far greater is the number of those who, in spite of all its interests, in spite of the satisfying consciousness of duty fulfilled, miss something, and long with an uncxpressed longing to have something more of life; and this longing is natural and reasonable, for man is a many-sided being. Late in the evening the sister seeks her room, her thoughts still bent upon the completed work of the day. One task has pressed hardly upon another. "Have I neglected nothing? Is all left just as it should be ?" "Have I realized all the responsibility of my calling?" One must indeed summon all one's energies to be a really good sister.

There are the almost forgotten letters from home-from friends. "I have sent them no word for so long a time, and $I$ so much enjoy being with them a short time in spirit, at least. To-day it is so late, $I$ am so tired, but to-morrow I,-yes, then I will make up for all neglect."

But to-morrow it is the same, and the next day, and the whole week. And as it is with the letters to distant friends, so with other things. "When shall I ever find time to read? - to give a quarter of an hour to my beloved music? How I would enjoy a little taste of art. I have, to be sure, one free half day in the week. How fortunate that now I can hear a good concert, or go to a classic play. I will go to the play."

But the hoped-for pleasure is spoiled through weariness. At midnight to stretch one's self upon one's couch seems the only thing worth while. "If it were only not so hard to rise after five and a half hours' sleep. The next half day I will be more sensible. I will rest myself well; perhaps I will take a walk. How long it is since I have enjoyed the woods and meadows, the blue sky, the sunshine! But my world is now the ward and my little room. How is it that I can. not always realize this?"

Can now those who, standing apart from the life of the nurse, consider it objectively, comprehend why it is forced into so narrow a groove? The sister must almost completely give up family, friends, and outside interests. She 
becomes more and more one-sided, and the consciousness of being behind the times, the left-out feeling when with people of wider outlook, together with the increasing lassitude of every year's work, reduce her finally to a condition of dulness.

The wish to carry on her work, which she truly loves, under easier conditions is indeed there, but she lacks the mental elasticity to struggle against circumstances, especially when to do so might risk her livelihood. These are the reasons why it is so seldom that a voice is raised from the ranks of nursing sisters. From my long service as head of a nursing staff $I$ can assert that many dis. tressing complaints reach my ears, and every year the conviction grows stronger that the old system must not be allowed to continue.

The fear will be expressed on many sides that if a nurse is able to cultivate outside interests her work will deteriorate. I believe, on the contrary, that her cheerful devotion to her work is often lost or changed to a spiritless routine, as a result of the excessive drains now made upon her strength. Health and physical and mental freshness are due to our work. Everyone knows the tonic influence of a cheerful, vigorous, and sympathetic personality upon the sick. It is being acknowledged in all branches of labor that rest and recreation are necessary ir one will bring fresh energy to one's work. Why may not this principle be carried into nursing?

Many who wish to study nursing are by its hardships compelled to decide against it, and to vary the theme at the beginning of my paper, I can say that many more educated women would find in it a congenial occupation if a reforma. tion in the system of work were possible. That this reformation must come slowly I well know. In Germany the best intentions must often wait for the necessary financial means. But it is a good sign when the general public begins to feel interest in the nurse's work and life. When that happens liberal minds will advocate more humane conditions and the nurse's labors will be mitigated. I hope that the Hamburg Association, which, though young, has already so much to be proud of, may become more and more emancipated.

\section{LETTERS}

\section{LETTER FROM ITALY}

(Continued from page 600)

Ospedale Clinico, Naples.

.. . I will not close without stating that during the year we have had about twelve or thirteen calls for nurses, both for private and hospital work. Of course, the pupils were not allowed to go, being still at the commencement of their training.

The only nursing they have attempted outside the hospital has been at the High School, of which the Princess is president, or in the homes of their own relations. In every case, except one which happened to be a case of measles, they have been obliged to attend the hospital as usual. The cases nursed were as follows: a typhoid case, of which my pupil took the night duty; a case of bloodpoisoning from tainted flsh; endometritis with profuse hemorrhage; malignant tumor of the thoracic cavity; uræmia (night duty); meningitis (night duty); the epidemic of measles above mentioned, in which my little pupil was isolated 